\title{
Rehabilitation of the visually impaired: opinions and expectations regarding individual limitations and the "Waiting-Group"
}

Rita de Cassia letto Montilha* Maria Inês Rubo de Souza Nobre* Newton Kara-José** Edméa Rita Temporini***

KEYWORDS: Low-Vision; Rehabilitation process; Blindeness.

ABSTRACT: This study searches out limitations and expectations of visually impaired customers attended to in a university service (CEPRE) in Campinas, State of São Paulo, Brazil, from 1994 to 1997, in order to get subsidies for improving the quality of the services offered. A special type of attendance called "waiting-group" is described with the customers' opinions regarding this kind of attendance being also surveyed during the rehabilitation process. Twenty subjects, aged 12 and more,

\footnotetext{
${ }^{1}$ Based on the Master's monograph [Rehabilitation of the visually impaired: characteristics, knowledge and opinions of customers attended to in a university service] - presented to the State University of Campinas/School of Medical Sciences for obtaining the Master's degree in neurological sciences, concentration area in ophthalmology. Campinas, State of São Paulo, Brazil, 1997.

* Master in Neurological Sciences, concentration area in ophthalmology, by the State University of Campinas/School of Medical Sciences; Occupational Therapist, Special Education and Rehabilitation teacher along with the Center for Studies and Researches in Rehabilitation "Prof. Dr. Gabriel Porto"CEPRE, a unity belonging to the State University of Campinas/School of Medical Sciences. Campinas, State of São Paulo, Brazil.

** Full Professor, Department of Ophthalmology, State University of Campinas/School of Medical Sciences, Campinas, State of São Paulo, Brazil; and Full Professor, Department of Ophthalmology, University of São Paulo/School of Medicine, São Paulo, State of São Paulo, Brazil.

*** Associate Professor, Lecturer in Methodology of Research for the Health Area, University of São Paulo/School of Public Health, São Paulo, State of São Paulo, Brazil; and, Research Counșellor for the
} 
with vision impairment, either congenital or acquired, compound the study sample. A questionnaire, employed for data collecting, disclosed: a slight predominance of males (57.0\%); average age equal to 32.2 ; the majority of the subjects are acquainted with the rehabilitation approach, presenting expectations as to the work developed by the service; among the opinions regarding limitations due to vision impairment, those associated with locomotion $(80.0 \%)$ and ability to exercise professional activities $(75.0 \%$ ) predominate; as to personal changes that came about as a result of taking part in the "waiting-group", that of the acceptance of the vision impairment prevails $(89.5 \%)$. Concluding, the Authors stress the need for vision rehabilitation programs to promptly attend the demand, in a mandatory way, taking into account both the customers' needs and opinions.

\section{INTRODUCTION}

The Authors' ten-year experience attending visually impaired persons coming from all parts of the country in a university service for vision rehabilitation (CEPRE) of national renown, provided them with quite a large knowledge on this area, at a national level. This background authorises them to state that, in Brazil, the majority of the rehabilitation services for the visually impaired are unable to cope with the demand. This can be put on account of various factors; among them: the attendance of this type of customers must necessarily be offered by an interdisciplinary team; it is an indispensable requisite that the process of attendance be individually carried out; the time spent by each professional of the interdisciplinary team in the attendance of the users can not be previously established, as it is also the case for the time required to obtain results from the vision rehabilitation process, since it depends on psychosocial, motor, cognitive and, sensorial factors, at an individual level.

Besides the reduced capacity of attendance of the Brazilian vision rehabilitation services, another factor of concern is that related to the access of the visually im-

discipline of Ophthalmology, State University of Campinas/School of Medical Sciences, Campinas, State of São Paulo, Brazil.

City: Campinas State: São Paulo Contry: Brazll

Rua Ministro Oscar Saraiva, 40 apto 24B ZIP: 13093-420

Phone: 55-19-2545446 Fax: 55-19-7888814

e-mail:rcietto@unicamp.br 
paired to these services. Rare are the cases of visually impaired individuals who know, look for and, succeed in being admitted for immediate attendance. There are cases of visually impaired persons who, although having some knowledge about the existence of rehabilitation services for the visually impaired, are too late in searching for them.

On the other hand, the person who looks for attendance in vision rehabilitation services usually faces a series of frustrations and difficulties, from the moment he is made cognisant of the diagnosis up to the realisation that there is no cure for his vision impairment.

- One of the orientations the users are provided with in services for vision rehabilitation is concerned with the possibilities available to the visually impaired to benefit from the rehabilitation attendance, giving them, for example, a perspective of a better quality of life and a higher degree of independence. However, when the patient ultimately makes up his mind and decides to participate in a process of vision rehabilitation, he has to wait, in general, a long time before being attended to, which might last more than a year. For this reason, new approaches of intervention have been proposed, such as the modality of attendance called "waiting-group".

KORNBLIT \& RASCOVSKY (1970) report that the origins of the "waiting-group" can be traced back to a Centre for Mental Health in Buenos Aires, Argentina (1968), where both a demand greater than the capacity of attendance and the lack of qualified technical staff caused the patients to wait large periods of time before being attended to. The "waiting-group" appeared with the purpose of providing the patients with a initial attendance, concomitantly with the psychological study carried out by other professionals.

GROISMAN and coll. (1978) point out that, in Brazil, the first reference to a "waiting-group" was observed in a work developed by Hezin along with the National Institute for Social Security, in the Psychiatric Clinic, in the city of Rio de Janeiro, in 1976: This modality of attendance was created taking into account the great number of patients waiting to be attended to in group therapy (determining an index of withdrawal of 1:4), aiming at "allowing better conditions of evaluation and investigating the possibilities of making the best use of the patients with a view to the treatment prescribed". 
From 1978 on, the adolescents ward of the Federal University of Rio de Janeiro Psychiatric Institute adopted this kind of procedure, considering it efficient not only as an aid to the diagnosis but also as an active and dynamic way of occupying the otherwise unproductive waiting time. (GROISMAN and coll., 1978).

The "waiting-group", target of the present paper, was first introduced at the CEPRE in 1991, as a modality of attendance in the Program for Visually Impaired Adolescents and Adults. From then on, the service obeys the following routine: after a screening carried out by the social service, the new patient is assigned to a group of visually impaired customers with a similar type of vision impairment (blindness or low-vision) who are waiting referral either to individual or group attendance with the different professionals of the interdisciplinary team-orientation and mobility teacher, occupational therapist, specialised pedagogue, social assistant and, dailyliving skills teacher.

The "waiting-group" attendance is developed once a week at the CEPRE, with onehour and a half schedule and a number of participants varying from 6 to 10 . This proposition of attendance is carried out in two phases.

At the first one, the target is to attend the user immediately after he seeks for rehabilitation. This phase, in charge of an occupational therapist, favours: the expression of the client's expectations concerning rehabilitation; the patient's verbalisation of the limitations he feels as due to his vision impairment; liberation of the patient's anxieties caused by the time he has to wait to be attended to; and, last but not least, an opportunity for the patient being enlightened about the purpose of the service. At this first stage, the dynamics of attendance occurs by means of verbalisation, on the part of the clients, of deep feelings about their vision impairment and performance of practical activities.

At the second phase, the meetings have as a goal to provide the users with orientations concerning the rehabilitation process, allowing them the performance of practical activities. At this stage, the other members of the professional team -physiotherapist, social assistant and, pedagogue-carry out their work, once a week, orienting and propitiating the clients the development of activities that have been recommended for that group. For example, walking safely in the streets; using optical and non-optical prescribed devices; starting to develop, independently, some activities of daily-living; getting a better acceptance of the vision impairment; get- 
ting to know specific resources and tools for written communication (computer skills, Braille system, vision amplification, among others).

This process of attendance introduces the user to vision rehabilitation and usually lasts around 10 weeks.

The present research took into account that this type of attendance is already an integrating part of the routine of the institution and the need for getting to know the opinions of the users concerning this modality of attendance. Therefore, the goals of the present research were to get to know: the opinions held by visually impaired persons attended to at this university service as to individual limitations due to their vision impairment; their expectations concerning the vision rehabilitation process; and, their opinions as to the benefits they felt from participating in the "waitinggroup".

With this research, the Authors intended to obtain information in order to get subsides for planning activities that might improve the rehabilitation practice for the visually impaired.

\section{MATERIAL AND METHODS}

This study was carried out following a descriptive survey pattern. The target-population was constituted of visually impaired individuals aged 12 and more, with bilateral vision impairment, either congenital or acquired, being attended to in the service, in its rehabilitation program for visually impaired adolescents and adults. A non-probabilistic convenience sample, size-20, was obtained according to the criteria of data collection feasibility and easy access to the customers. Users being attend to in the service were interviewed in the period from November, 1996 to March, 1997.

An exploratory study was carried out with a view to work out a questionnaire that would be the measurement instrument of the research. This methodological resource is an integrating part of the main research, constituting a preliminary study carried out in order to best adequate the measurement instrument to the reality to be studied (PIOVESAN \& TEMPIRINI, 1995). 
This instrument was submitted to a pre-test carried out with clients being routinely attended to at the CEPRE. After some needed alterations had been made, the questionnaire was then applied to the population under study, with both its validity and reliability being assessed (questionnaire in annex).

Data processing and data analysis were performed using both the EPI INFO program, 6.0 version (DEAN et al., 1994) and the Statistical Analysis System-SAS.

\section{RESULTS AND DISCUSSION}

Among the characteristics of the sample, the following could be observed: there was a somewhat equivalence between males $(56.0 \%)$ and females (44.0\%); the age ranged between 13 and 63 years, with an average age equal to 32.2 ; a predominance of low-vision individuals $(85.0 \%$ ) was found out in this study; $95.0 \%$ of them were acquainted with their ophthalmologic impairment, the cause of their vision. problem. Among the causes of the vision impairments of the individuals of the sample, the following ones were found out: atrophy of the optical nerve (21.0\%); pigmentary retinosis $(15.7 \%)$; congenital cataract $(15.7 \%)$; and, with a percentage equal to $5.3 \%$ for each of them, the ahead mentioned optical conditions were also found out: glaucoma, congenital glaucoma, major myopia, optic neuritis, ocular trauma, juvenile macular degeneration and retrolental fibroplasia. It is worth emphasising that in $85.0 \%$ of the cases of the sample, the vision impairment was acquired either in the adolescence or in the adult life.

As to the limitations the visually impaired individuals of the sample felt as due exclusively to their vision impairment, it can be observed on Table 1 that walking around without help is the item presenting the greatest proportion of responses $(80.0 \%)$, followed by restrictions to exercise professional activities: $75.0 \%$ reported having never worked or having left the work due to the vision impairment.

It is known that for every ordinarily active adult who loses his vision, the loss of mobility is an essential loss, since it means more than simply walking; it means independence, freedom to go from a place to another using all the resources an individual generally uses, be it within the small space of a living room or a house in which he works or lives in, be it in local or broad geographic areas (CARROL, 1968). 
Coherently with data related to loss of mobility, it can be observed on the same Table 1 that $55.0 \%$ of the respondents indicated stroll and $10.0 \%$, engaging in sports, as activities that had been limited as a result of their vision impairment. It is worth mentioning once again that locomotion appears as a limiting factor, since it directly interferes with the performance of these activities.

Data on Table 1 point out that an expressive proportion of the persons interviewed (respectively, $60.0 \%$ and $55.0 \%$ ) perceives the restriction to reading and writing as an important problem. These data might be indicating the need, on the part of rehabilitation programs, for focusing on teaching the visually impaired how to use the prescribed optic aids or the Braille system.

On Table 2, coherently with data observed on Table 1, related to the limitations to locomotion due to vision impairment, it can be observed among the respondents the predominance of the expectation to learn how to walk around without help (75.0\%).

Still commenting data on Table 2, the items starting to work $(66.6 \%)$ and resuming work $(63.6 \%)$ portray expectations already anticipated by the authors, since adult life is a time for productive work and the vision impairment might interfere with conditions required to exercise determined professional activities. The percentage related to customers that do not hold expectations as to the rehabilitation process being able to propitiate them beginning to work or resuming work might be attributed to individuals who are already retired due to their vision disability or to those who are in a period of life considered as not yet apt to work.

On Table 2, it is also worth mentioning among the expectations, the interest disclosed in learning how to use the prescribed eyeglasses (58.9). These data might be suggesting the need for specific orientation on the use or adequate employment of optic aids on the part of the low-vision individuals (KARA-JOSÉ et al., 1986; KELLER, 1979; WIENER \& VOPOTA,1989).

According to WATSON (1989) and CARVALHO (1993), the client who has to use optic and non-optic aids needs general orientation on how to maximise his residual vision by means of sequential instructional techniques. 
As it can be seen on Table 3, in relation to the changes that came about as a result of participating in the "waiting-group", the items beginning to accept the vision impairment (89.5) and crossing the streets using adequate help (63.1\%) out-stood amongst the opinions declared.

The feelings during this process of acceptance of the vision impairment are, in general, those of ambivalence, rebellion, anxiety, anguish, denial of the impairment and, hope of healing.

Data on Table 3 give support to the hypothesis that the exchange of experiences among persons presenting similar difficulties are likely to favour both identification and expression of feelings. In addition, this exchanging of experiences appears to facilitate the reception of orientations and the elaboration of feelings related to the vision loss.

With some reservations, one might transpose to the instance of acceptance of the vision loss the same four phases of "elaboration of mourning" proposed by BOWLBY (1979): (1) apathy; (2) longing and searching for the lost figure; (3) disorganisation and despair; and, ultimately, (4) reorganisation. In the case of the vision loss, apathy would seize the individual immediately after he is made aware of the fact, usually lasting from some hours to a whole week, being likely to be interrupted by extremely intense outbursts of consternation and/or anger. In the phase of the longing and searching for the lost figure, the visually impaired person would begin, though episodically, to become aware of the reality of his loss; this would lead him to an incessant search for healing by paying calls to different medical and non-medical services. The third phase, that of the disorganisation and despair, would be that where there would be a greater expression of feelings of rage, search for guilty parts and, depression. Finally, the fourth phase, that of the reorganisation, would be the moment of the greatest level of acceptance of the vision loss, when this loss would be ultimately accepted as a consummate fact and when, consequently, would exist a greater involvement of the visually impaired individual with the vision rehabilitation process.

MONTILHA (1996) emphasises that the low-vision client would only benefit from the orientations he receives, from his self-experiences with materials, from optic adaptations and devices if he is actually aware of his skills, his limitations and if he has a reasonable dose of self-esteem. 
The target of the "waiting-group" attendance for the visually impaired is to welcome the person who, in the majority of the cases, has recently lost his vision and still is in the hope of getting healed. The activities developed there aim at favouring the expression of feelings in order that the process of "elaboration of mourning" get started, which, in this case, would constitute the acceptance of the vision loss. This process is influenced by the individual's personality, by his previous feelings concerning vision impairment and by how he experienced the first losses that have their beginning when the first separations from the maternal bond occurred. (VIORST, 1986).

It can be also observed on Table 3 , although with a reduced frequency, that other changes were declared, portraying aspects associated with self-esteem, utilisation of optic aids and locomotion. These aspects are intimately interrelated, expressing a likely acceptance of the vision loss. Such results appears to authorise the statement that the participation in the "waiting-group" modality propitiated greater interest and better understanding of the rehabilitation process on the part of the target population.

In this context, it is worth emphasising the importance of the vision rehabilitation service for visually impaired individuals in favouring the expression of feelings that would trigger the process of acceptance, enhance the exchanging of experiences with other persons presenting similar difficulties, besides providing them with knowledge on, and awareness of, the rehabilitation process. These would be, for the Authors, the ideal purposes of the "waiting-group", in addition to general orientation aiming at accelerating the achievement, on the part of the visually impaired individuals, of a better quality of life and favouring their adhesion to the rehabilitation program with a view to their reaching a desired level of independence. 
Table 1. Opinions on the limitations imposed by visual impairment.

$\mathrm{n}=25$

\begin{tabular}{|c|c|c|c|c|}
\hline \multicolumn{5}{|l|}{ Limitations } \\
\hline & \multicolumn{2}{|c|}{ Yes } & \multicolumn{2}{|c|}{ No } \\
\hline & $f$ & $\%$ & $f$ & $\%$ \\
\hline Walk alone & 17 & 68,0 & 8 & 32,0 \\
\hline Work & 16 & 64,0 & 9 & 36,0 \\
\hline Read & 14 & 56,0 & 11 & 44,0 \\
\hline Write & 13 & 52,0 & 12 & 48,0 \\
\hline Stroll for pleasure & 13 & 52,0 & 12 & 48,0 \\
\hline Cook alone & 8 & 32,0 & 17 & 68,0 \\
\hline Attend school & 7 & 28,0 & 18 & 72,0 \\
\hline Converse with friends & 6 & 24,0 & 19 & 76,0 \\
\hline Drive a car & 5 & 20,0 & 20 & 80,0 \\
\hline Eat alone & 3 & 12,0 & 22 & 88,0 \\
\hline Converse with the family & 3 & 12,0 & 22 & 88,0 \\
\hline Practice sports & 3 & 12,0 & 22 & 88,0 \\
\hline
\end{tabular}

Table 2. Expectations that the visually impaired have with regard to the rehabilitation program.

Expectations

$\begin{array}{lrc} & f & \% \\ \text { Learn to walk alone }(n=25) & 19 & 76,0 \\ \text { Start working ( } n=11) & 9 & 64,2 \\ \text { Return to their jobs }(n=14) & 9 & 64,2 \\ \text { Learn to use the prescribed spectacles }(n=17) & 10 & 58,9 \\ \text { Use the computer ( } n=25) & 13 & 52,0 \\ \text { Learn to cook alone }(n=25) & 13 & 52,0 \\ \text { Learn to look after the home alone (n=25) } & 10 & 40,0 \\ \text { Read and write }(n=25) & 9 & 36,0 \\ \text { Cure the visual impairment (n=25) } & 8 & 32,0 \\ \text { Develop visual efficiency ( } n=17) & 5 & 29,4 \\ \text { Learn to eat alone }(n=25) & 6 & 24,0 \\ \text { Accept the visual problem (n=25) } & 5 & 20,0 \\ \text { Return to school ( } n=23) & 4 & 17,4 \\ \text { Start going to school }(n=12) & 2 & 16,7\end{array}$


Table 3. Opinion of the visually impaired with regard to the changes brought about by the "work-group".

Opinion

Changed

Did not change

Changes :

f

$\%$

Got to know other people with similar problems $(n=19)$

Started accepting the problem. $(n=19)$

$19 \quad 100,0$

17

89,5

Began crossing the road with the help of another person $(n=19)$

12

63,1

Started using spectacles $(n=17)$

$5 \quad 29,4$

Gave his own life more value $(n=17)$

Started walking without running risks . $(n=16)$
$5 \quad 26,3$

$4 \cdot 25,0$

\section{CONCLUSIONS}

1. Among the limitations due to vision impairment expressed by the respondents, those concerned with locomotion without help and exercising professional activities out-stood.

2. The expectations related to the rehabilitation process were concerned, mainly, with the autonomous locomotion and the beginning of, or resuming, professional activities.

3. According to the respondents' perception, the "waiting-group" was a satisfactory modality of attendance in helping them to accept their vision loss; in providing them with the initial steps on locomotion; and, in favouring their adhesion to the rehabilitation process. 


\section{REFERENCES}

Bowlby, J. (1979). The making and breaking of affectional bonds. London: R.P.L.

Carrol, T.J. (1968). A cegueira. Brasília: Campanha Nacional de Educação dos Cegos, Ministério da Educação e Cultura.

Carvalho, K.M.M.(1993). Visão Subnormal: apresentação de um modelo de atendimento e caracterização das condições de diagnóstico e tratamento em um serviço universitário do Brasil. Campinas, [Tese - Doutorado - Faculdade de Ciências Médicas - UNICAMP].

Dean, A.G.; Dean, J.A.; Coulombier, P.; Brendel, K.A.; Smith, D.C.; Burton, A.H.; Dicker, R.C.; Sullivan, K.; Fagan, R.F; Arner, T.G. (1994). Epi info, version 6: a word processing, database, and statistics program for epidemiology on microcomputers. Atlanta: Center for Desease Control and Prevention.

Groisman, M.; Orlandi, A.L.; Quintes, H.M.F.; Tróia, M.C.C.; Maranhão, M.L.A. (1979). Grupo de espera: uma perspectiva institucional de atendimento imediato ao adolescente. In: CONGRESSO BRASILEIRO DE GRUPO, 4, Rio de janeiro, Gradiva. Rio de janeiro.

Kara-José, N.; Arieta, C.E.L.; Temporini, E.R.; Kang, K.M.; Ambrósio, L.E. (1996). Tratamento cirúrgico de catarata senil: óbices para o paciente. Arq. Bras. Oftal., 59(6), 573-77.

Keller, D.D. (1979). Orientation to low vision aids. J. Vis. Impairm. Blind., 73(5), 16166.

Kornblit, A. \& Rascovsky, A. (1970). Importancia institucional de los Llamados Grupos de espera. Revista Argentina de psiquiatria de la infancia y de la adolescencia, $1(1), 55-60$.

Montilha, R.C.I. (1996). Visão subnormal e a abordagem da terapia ocupacional. Arq. Bras. Oftal., 59(4), 354.

Piovesan, A. \& Temporini, E. R. (1995). Pesquisa exploratória: procedimento metodológico para o estudo de fatores humanos no campo da saúde pública. Revis. Saúde Públ., 29, 318-25.

Viorst, J. (1986). Necessary Losses. New York: Simon and Schuster. 
Watson, G.(1989). Competencies and bibliography addressing student's use of low vision devices. J. Vis. Impairm. Blind., 83:160-63.

Wiener, W.; Vopata, A. (1989). Suggested curriculum for distance vision training with optical aids. J. Vis. Impairm. Blind., 83, 49-56.
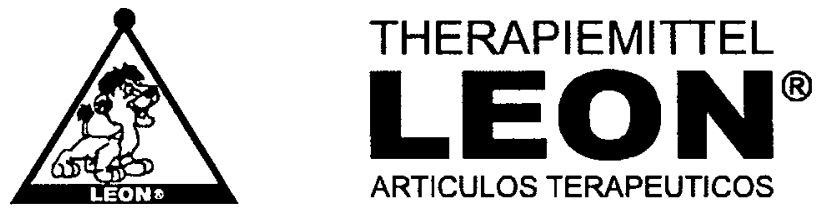

ARTICULOS TERAPEUTICOS

PRODUCTOS DIRECTAMENTE IMPORTADOS DE ALEMANIA APROBADOS POR EL INSTITUTO DE CALIDAD Y SEGURIDAD ALEMANA TÜV ESTIMULACION SENSORIAL DESARROLLO psICOMOTOR PERCEPCION VISUAL Y TACTIL SISTEMA VESTIBULAR (EQUILIBRIO) ESTABILIDAD DEL PATRON FLEXOR Y DEL TRONCO

Carrera 75 No. 49A-16 Teléfono: 4162374 Fax: 4299284 e-mail: LEON.Colombia@hotmail.com Bogotá, D.C. - Colombia Website: www.leoncompany.cjb.net 